\title{
A 25-Year-Old Male with Orogenital Ulcers, Rash, and Difficulty Swallowing
}

\author{
Lauren N. Ko ${ }^{a} \quad$ Allireza Alloo $^{d} \quad$ William M. Lin ${ }^{a, b} \quad$ Mai P. Hoang ${ }^{a, c}$ \\ Daniela Kroshinsky a, b \\ ${ }^{a}$ Harvard Medical School, Departments of ${ }^{b}$ Dermatology and ${ }^{\mathrm{C}}$ Pathology, Massachusetts \\ General Hospital, Boston, MA, and d Department of Dermatology, Northwell Health, \\ Lake Success, NY, USA
}

\section{Keywords}

Behçet disease $\cdot$ Orogenital ulcers

\begin{abstract}
A 25-year-old otherwise healthy male presented with new-onset odynophagia, rash, and orogenital ulcers. Despite treatment with antibiotics for presumed bacterial pharyngitis, the patient remained symptomatic, with abnormal vital signs and laboratory values. Upon dermatology consultation and histopathologic correlation, he was diagnosed with Behçet disease. Behçet disease is a rare rheumatologic condition that presents with recurrent oral ulcers and varying degrees of ophthalmic, neurologic, cardiac, and vascular disease. Given its protean nature, the treatment of Behçet disease is tailored to the patient's presentation and severity of organ involvement. Following treatment with colchicine and prednisone, the patient's symptoms improved rapidly.

(C) 2017 The Author(s)

Published by S. Karger AG, Basel
\end{abstract}

\section{Case Report}

A 25-year-old male with no past medical history presented with odynophagia, new rash, and orogenital ulcerations. Shortly after labral repair of the right hip 18 days prior to admission, the patient developed pharyngitis, odynophagia, fevers, chills, and night sweats. He was treated with amoxicillin for a presumed bacterial pharyngitis by his primary care physician who noted anterior cervical lymphadenopathy, tonsillar enlargement, and erythema on examination. At that time, he also noted headaches, myalgias in his bilateral thighs and

Daniela Kroshinsky, MD, MPH

Department of Dermatology, Massachusetts General Hospital

50 Staniford Street, 2nd Floor

Boston, MA 02114 (USA)

E-Mail dkroshinsky@partners.org 

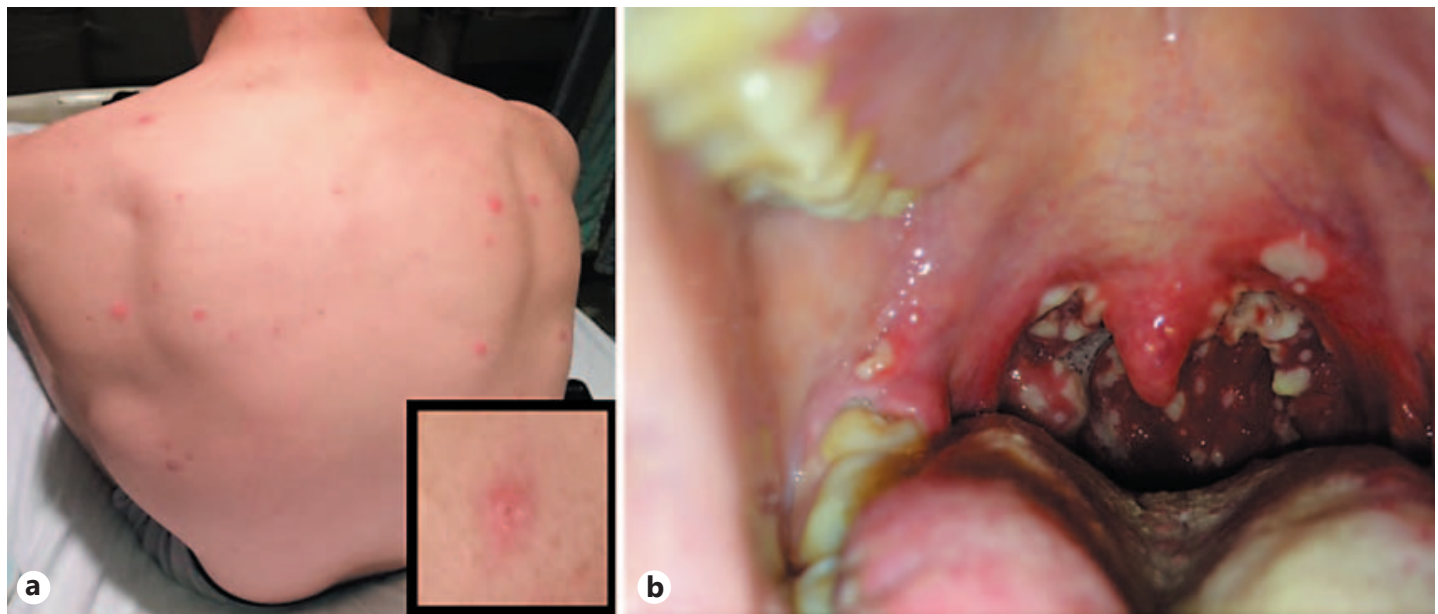

Fig. 1. a Scattered erythematous papules and pustules on the back and some papules with faint surrounding collarets of scale on the trunk (inset). $\mathbf{b}$ Grouped clean-based ulcerations in the posterior oropharynx.

calves, as well as a recent weight loss of approximately 7-8 pounds. Despite treatment with amoxicillin, the patient remained febrile with ongoing pharyngitis and was seen again by his primary care physician; he was switched to amoxicillin-clavulanate. Heterophile antibodies were negative and liver and renal function tests were within normal limits. He subsequently developed oral and genital ulcers, worsening odynophagia, and a pustular rash on his face, trunk, and limbs, prompting admission.

He was admitted to hospital and treated with ampicillin-sulbactam and acyclovir as well as with hydromorphone, acetaminophen, ibuprofen, and morphine to control his oral pain. On examination, temperature was $37.1^{\circ} \mathrm{C}$. Cutaneous examination was notable for scattered intact pustules and papules with collarets of scale on the face, trunk, and extremities (Fig. 1a) along with tender erythematous nodules on the bilateral shins. Orogenital examination revealed grouped clean-based ulcerations on the vermillion lips and soft palate, erythematous clustered erosions on the tonsils (Fig. 1b), and clean-based ulcers on the scrotum and glans penis. Of note, there was no involvement of the palms or soles. Three-millimeter punch biopsies were performed on the lower lip and shoulder.

Initial laboratory studies were notable for leukocytosis $\left(21,000 / \mathrm{mm}^{3}\right.$ with $82 \%$ polymorphonuclear leukocytes) and elevated C-reactive protein $(236 \mathrm{mg} / \mathrm{L})$, erythrocyte sedimentation rate $(90 \mathrm{~mm} / \mathrm{h})$, and ferritin $(481 \mathrm{ng} / \mathrm{mL})$. Rapid strep, human immunodeficiency virus, and heterophile antibody tests were all negative. A viral polymerase chain reaction of the patient's penis/lip ulcers were negative for herpes simplex virus, blood cultures demonstrated no growth, and wound culture of a pustule on his shoulder was also negative for microorganisms.

Histopathologic examination of the lower lip revealed an ulcerated squamous epithelium with underlying dense infiltrate of neutrophils, histiocytes, and lymphocytes (Fig. 2a). Fibrinoid necrosis of the walls of the small vessels and perivascular and interstitial infiltrate of neutrophils, histiocytes, and lymphocytes were noted, all supportive of small-vessel vasculitis (Fig. 2b). The biopsy from the shoulder demonstrated acute folliculitis and focal adjacent small-vessel vasculitis with associated karyorrhectic debris.

These histopathologic findings in conjunction with the patient's orogenital ulcerations, papulopustular eruption, likely erythema nodosum on the lower extremities, and systemic symptoms were consistent with a diagnosis of Behçet disease. Colchicine (0.6 mg twice daily) 

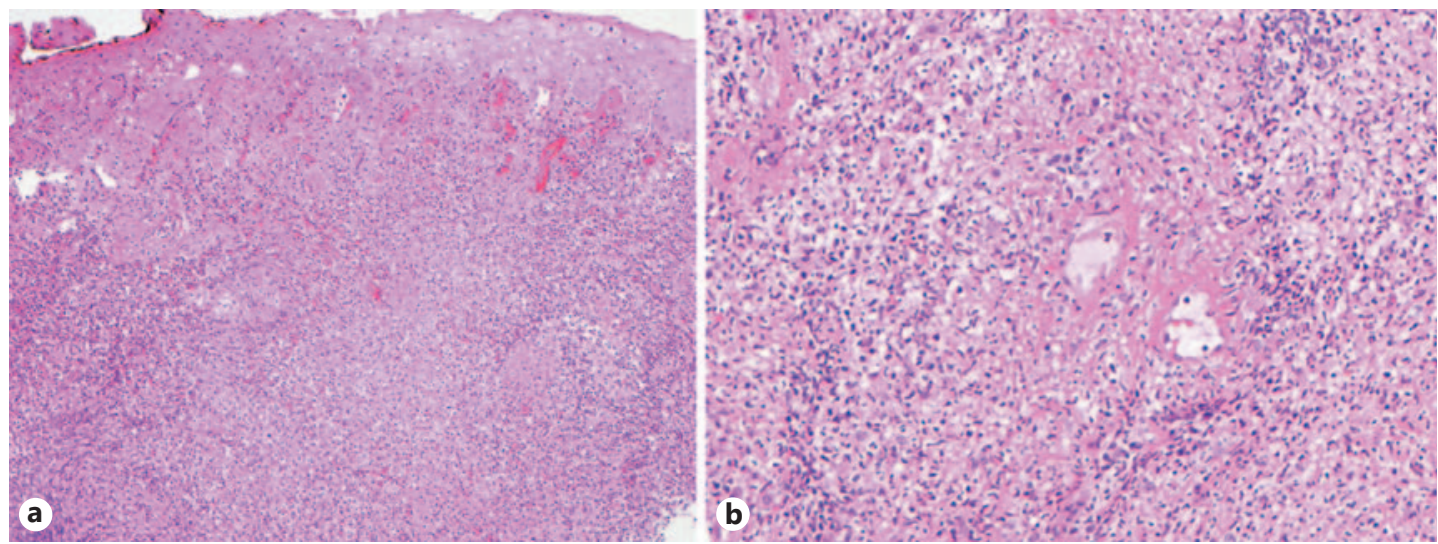

Fig. 2. a The punch biopsy of the lower lip showed a dense inflammatory infiltrate of neutrophils, histiocytes, and lymphocytes (low-power view of H\&E, ×100). b Fibrinoid necrosis of the vessel walls was noted, consistent with a small-vessel vasculitis (higher-power view of $\mathrm{H} \& \mathrm{E}, \times 400$ ).

was initiated to treat the patient's skin lesions and arthritis. Prednisone was also administered to manage his ongoing odynophagia. Ophthalmology was consulted to rule out the possibility of occult ocular involvement and confirmed no inflammatory eye disease. Within $24 \mathrm{~h}$, the patient demonstrated improved oral symptoms and resolving cutaneous exanthem. Upon discharge, he was prescribed a prednisone taper and colchicine as well as follow-up with rheumatology.

\section{Discussion}

Behçet disease is a rare rheumatologic condition first described in 1937 by its namesake Hulusi Behçet. Common among young adults, Behçet disease is most prevalent in individuals of Mediterranean, Middle-Eastern, and Far-Eastern descent [1, 2].

Though it may affect nearly every organ system, Behçet disease is classically characterized by recurrent orogenital ulcerations, inflammatory ocular disease, and small-vessel vasculitis [3]. Neutrophilic cutaneous eruptions, arthritis, as well as gastrointestinal and neurologic disease may also present to varying degrees [4]. Clinically, Behçet disease often presents with painful oral aphthous ulcers on the lips, cheeks, tongue, palate, or pharynx, essentially indistinguishable from common canker sores. However, unlike common aphthous ulcers, ulcerations in Behçet disease are typically larger, grouped, and take longer to heal, as seen in this case [5]. With regard to distribution, the aphthous ulcers of Behçet disease typically occur on non-keratinized mucosa, which differentiates them from those of recurrent herpes simplex, which have a predilection for keratinized mucosa [6]. Genital ulcers, which occur in $75-80 \%$ of patients, are the most specific sign [7]. Most often found on the penile shaft or scrotum in men and the vulva in women, these ulcers can take weeks to months to heal and often scar [7].

Skin eruptions, which occur in approximately $75 \%$ of patients, include acneiform lesions, erythema nodosum, superficial thrombophlebitis, and purpura $[4,8,9]$. Pathergy, though not sensitive, is a highly specific sign of Behçet disease, as many patients develop a sterile pustule within $48 \mathrm{~h}$ of minor skin trauma, such as a needle stick [10]. These reactions are more common in patients from endemic areas (50-60\%) than in North American and European patients with Behçet disease (10-20\%) [11]. Acneiform lesions, as were seen in this patient, 
are difficult to distinguish from the papules and pustules of ordinary acne and typically exhibit similar microbiologic flora [12].

Although not seen in our case, ocular disease, most commonly in the form of retinal vasculitis, hypopyon, and anterior/posterior uveitis, affects a majority of Behçet disease patients [13]. Other manifestations include central nervous system disease, renal involvement (i.e., secondary amyloidosis, interstitial nephritis), vascular abnormalities, and cardiac involvement (i.e., pericarditis, myocarditis) [14].

There are no pathognomonic diagnostic tests for Behçet disease; however, specific criteria exist to aid in making the diagnosis [7]. Specifically, Behçet disease is suggested when a patient presents with recurrent oral aphthae, in addition to any two of the following: ocular pathology as described above, recurrent genital ulcers, skin lesions, or a positive pathergy test (papule $\geq 2 \mathrm{~mm}$ developing $<48 \mathrm{~h}$ after insertion of a 20 -gauge needle $5 \mathrm{~mm}$ into the skin) [7].

The histologic features of Behçet disease are nonspecific and are only confirmatory in the appropriate clinical context. Early lesions show superficial ulceration with associated acute inflammatory infiltrate. Only $50 \%$ of biopsies will reveal leukocytoclastic or lymphocytic vasculitis, as was seen in this patient's histology. In addition to acneiform lesions and ulcers, other histopathologic features include erythema nodosum-like lesions and superficial thrombophlebitis [15-17].

In our patient, the presence of oral and genital ulcers, a papulopustular skin eruption, arthritis, and shin nodules suspicious of erythema nodosum were clinically suggestive of Behçet disease. The corresponding histologic finding of small-vessel vasculitis was consistent with this diagnosis.

Typically, Behçet disease is characterized by a relapsing-remitting course; however, it has been found to be more severe in young men of Middle-Eastern or Far-Eastern descent [18]. The greatest causes of morbidity and mortality include neurologic disease, ocular involvement, and large-vessel abnormalities, which can result in gastrointestinal bleeding, arterial aneurysms, and Budd-Chiari syndrome, among others $[19,20]$. Despite the possibility of widespread disease involvement, large cohort studies have shown low mortality rates $(0.3-5 \%)$ at median follow-up periods between 7 and 9 years $[19,20]$.

The treatment of Behçet disease is complex given its mercurial nature, and should be tailored based on the individual patient's disease severity and specific organ involvement. Nevertheless, given the likelihood of vital organ involvement along with the recurrent nature of the disease, early and aggressive treatment is of critical importance. For mucocutaneous lesions, topical steroids and anesthetics can be effective for isolated ulcerations, while intralesional glucocorticoids can be used for larger ulcers. Topical sucralfate $(1 \mathrm{~g} / 5 \mathrm{~mL} 4$ times daily) has also been found to reduce the pain and healing time of oral ulcers [21]. Both aphthae and arthritis can be treated with colchicine (1-2 mg/day), nonsteroidal anti-inflammatory drugs, and low-dose prednisone (5-10 mg/daily) for maintenance [22-24]. Severe or refractory cases of Behçet disease may require higher doses of systemic glucocorticoids. The treatment of other involved organ systems depends on the nature of disease presentation. For example, topical glucocorticoids and scopolamine are used for anterior uveitis [25]. Azathioprine and systemic glucocorticoids are considered the first-line treatment for both posterior uveitis and neurologic manifestations, such as encephalitis and central nervous system vasculitis [26-29]. When there is arterial involvement, a combination of medical and surgical treatments can be employed. Given the recurrent nature of the disease, a variety of immunomodulatory/immunosuppressive agents such as cyclosporine, methotrexate, cyclophosphamide, and anti-tumor necrosis factor alpha inhibitors can be utilized for long-term disease maintenance [30-35]. 


\section{Statement of Ethics}

This paper was prepared in compliance with all ethical and confidentiality guidelines and principles. The patient gave his informed consent for publication.

\section{Disclosure Statement}

The authors have no conflicts of interest to disclose.

\section{References}

1 Krause I, Weinberger A: Behçet's disease. Curr Opin Rheumatol 2008;20:82-87.

-2 Calamia KT, Wilson FC, Icen M, Crowson CS, Gabriel SE, Kremers HM: Epidemiology and clinical characteristics of Behçet's disease in the US: a population-based study. Arthritis Rheum 2009;61:600-604.

-3 Sakane T, Takeno M, Suzuki N, Inaba G: Behçet's disease. N Engl J Med 1999;341:1284-1291.

4 Kokturk A: Clinical and pathological manifestations with differential diagnosis in Behçet's disease. Patholog Res Int 2012;2012:690390.

5 Bang D, Hur W, Lee ES, Lee S: Prognosis and clinical relevance of recurrent oral ulceration in Behçet's disease. J Dermatol 1995;22:926-929.

-6 Mortazavi H, Safi Y, Baharvand M, Rahmani S: Diagnostic features of common oral ulcerative lesions: an updated decision tree. Int J Dent 2016;2016:7278925.

-7 Criteria for diagnosis of Behçet's disease. International Study Group for Behçet's Disease. Lancet 1990;335: 1078-1080.

8 Onder M, Gürer MA: The multiple faces of Behçet's disease and its aetiological factors. J Eur Acad Dermatol Venereol 2001;15:126-136.

9 Demirkesen C, Tüzüner N, Mat C, et al: Clinicopathologic evaluation of nodular cutaneous lesions of Behçet syndrome. Am J Clin Pathol 2001;116:341-346.

10 Tüzün Y, Altac M, Yazici H, et al: Nonspecific skin hyperreactivity in Behçet's disease. Haematologica 1980;65: 395-398.

-11 Dinc A, Karaayvaz M, Caliskaner AZ, Pay S, Erdem H, Turan M: Dermographism and atopy in patients with Behçet's disease. J Investig Allergol Clin Immunol 2000;10:368-371.

12 Hatemi G, Bahar H, Uysal S, et al: The pustular skin lesions in Behçet's syndrome are not sterile. Ann Rheum Dis 2004;63:1450-1452.

13 Tugal-Tutkun I, Onal S, Ozyazgan Y, Soylu M, Akman M: Validity and agreement of uveitis experts in interpretation of ocular photographs for diagnosis of Behçet uveitis. Ocul Immunol Inflamm 2014;22:461-468.

14 Akpolat T, Akkoyunlu M, Akpolat I, Dilek M, Odabas AR, Ozen S: Renal Behçet's disease: a cumulative analysis. Semin Arthritis Rheum 2002;31:317-337.

15 Ozluk E, Balta I, Akoguz 0, et al: Histopathologic study of pathergy test in Behçet's disease. Indian J Dermatol 2014;59:630.

-16 Kutlubay Z, Mat CM, Aydin Ö, et al: Histopathological and clinical evaluation of papulopustular lesions in Behcet's disease. Clin Exp Rheumatol 2015;33(6 suppl 94):S101-S106.

17 Misago N, Tada Y, Koarada S, Narisawa Y: Erythema nodosum-like lesions in Behçet's disease: a clinicopathological study of 26 cases. Acta Derm Venereol 2012;92:681-686.

18 Kural-Seyahi E, Fresko I, Seyahi N, et al: The long-term mortality and morbidity of Behçet syndrome: a 2-decade outcome survey of 387 patients followed at a dedicated center. Medicine (Baltimore) 2003;82:60-76.

19 Saadoun D, Wechsler B, Desseaux K, et al: Mortality in Behçet's disease. Arthritis Rheum 2010;62:2806-2812.

20 Yazici H, Başaran G, Hamuryudan V, et al: The ten-year mortality in Behçet's syndrome. Br J Rheumatol 1996; 35:139-141.

-21 Alpsoy E, Er H, Durusoy C, Yilmaz E: The use of sucralfate suspension in the treatment of oral and genital ulceration of Behçet disease: a randomized, placebo-controlled, double-blind study. Arch Dermatol 1999;135:529_ 532.

-22 Yurdakul S, Mat C, Tüzün Y, et al: A double-blind trial of colchicine in Behçet's syndrome. Arthritis Rheum 2001;44:2686-2692.

23 Hamuryudan V, Hatemi G, Tascilar K, et al: Colchicine in Behçet syndrome: a longterm survey of patients in a controlled trial. J Rheumatol 2014;41:735-738.

24 Taylor J, Glenny AM, Walsh T, et al: Interventions for the management of oral ulcers in Behçet's disease. Cochrane Database Syst Rev 2014;9:CD011018.

-25 Hatemi G, Silman A, Bang D, et al: EULAR recommendations for the management of Behçet disease. Ann Rheum Dis 2008;67:1656-1662. 
26 Yazici H, Pazarli H, Barnes CG, et al: A controlled trial of azathioprine in Behçet’s syndrome. N Engl J Med 1990; 322:281-285.

27 Hamuryudan V, Ozyazgan Y, Hizli N, et al: Azathioprine in Behçet's syndrome: effects on long-term prognosis. Arthritis Rheum 1997;40:769-774.

28 Kalra S, Silman A, Akman-Demir G, et al: Diagnosis and management of neuro-Behçet's disease: international consensus recommendations. J Neurol 2014;261:1662-1676.

29 Al-Araji A, Kidd DP: Neuro-Behçet's disease: epidemiology, clinical characteristics, and management. Lancet Neurol 2009;8:192-204.

-30 Lee JH, Cheon JH, Jeon SW, et al: Efficacy of infliximab in intestinal Behçet's disease: a Korean multicenter retrospective study. Inflamm Bowel Dis 2013;19:1833-1838.

-31 Kaklamani VG, Kaklamanis PG: Treatment of Behçet's disease - an update. Semin Arthritis Rheum 2001;30: 299-312.

-32 Atmaca LS, Batioğlu F: The efficacy of cyclosporin-A in the treatment of Behçet's disease. Ophthalmic Surg 1994;25:321-327.

-33 Díaz-Llopis M, Salom D, Garcia-de-Vicuña C, et al: Treatment of refractory uveitis with adalimumab: a prospective multicenter study of 131 patients. Ophthalmology 2012;119:1575-1581.

-34 Cantini F, Niccoli L, Nannini C, et al: Efficacy of infliximab in refractory Behçet's disease-associated and idiopathic posterior segment uveitis: a prospective, follow-up study of 50 patients. Biologics 2012;6:5-12.

35 Davatchi F, Shams H, Shahram F, et al: Methotrexate in ocular manifestations of Behçet's disease: a longitudinal study up to 15 years. Int J Rheum Dis 2013;16:568-577. 